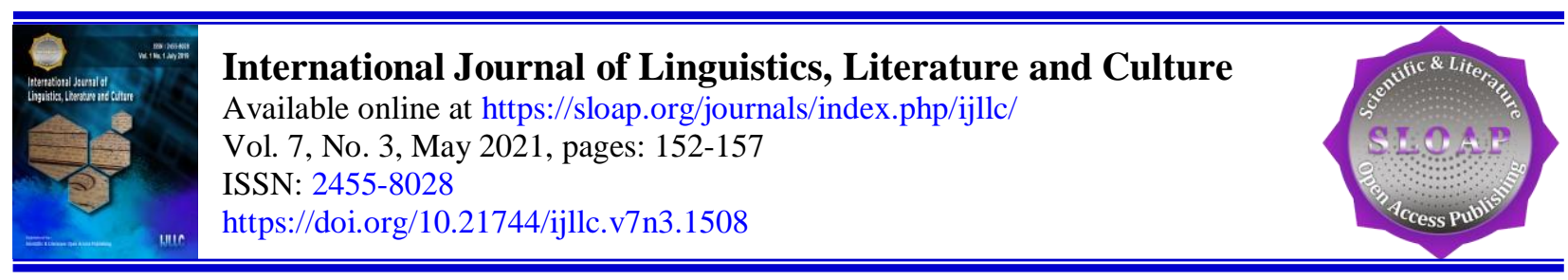

\title{
National Followers in the Students Use of Educational Technologies Instruction of Interests
}

Shomirzayev M.Kh. ${ }^{a}$

\section{Article history:}

Submitted: 9 February 2021

Revised: 27 March 2021

Accepted:18 April 2021

\section{Keywords:}

attitude;

communication;

component;

creativity;

development;

education;

ideology;

intellect;

interests;

national skill;

technology;

training;

voluntarism;
International journal of linguistics, literature and culture (C) 2021. This is an open access article under the CC BY-NC-ND license (https://creativecommons.org/licenses/by-nc-nd/4.0/).

\section{Corresponding author:}

Shomirzayev M.Kh.

Termez, Uzbekistan Phone: +998 762217455

Email address: shomirzaevm@tersu.uz.

\footnotetext{
${ }^{a}$ Termez State University, Termez, Uzbekistan
} 


\section{Introduction}

Modern stages of development of our education system, modern national and historical and ideological conditions of modern pedagogical and information and communication technologies, traditional models of education, classroom lesson in secondary schools, secondary special and professional colleges, lectures and seminars in higher education institutions the use of technologies that are appropriate for this period will undoubtedly have a positive effect while teaching methods such as this one. From this point of view, the education system of many developed countries has been widely used in countries such as "collaborative learning", "method of projects", "differentiated instruction", " teachers' folders "," individual and diverse approach to teaching ". In applying these in their work experience, it is important to avoid administrative burden when it comes to the principle of voluntarism. In this case, administrative intervention can only be an organizational-pedagogical, material base for their use, as well as in the process of teaching and equipping educational institutions. The teacher should be able to choose from which of them (Oudeyer et al., 2016).

In addition to the above-mentioned conditions for selecting technologies such as teaching, project methodology, classroom teaching, readership, widely used in developed countries, the DTS, which has been developed without the use of existing teaching technologies in classroom, lecture, seminars, but also to the formulation of students' knowledge (rating, test). Another important aspect of the modern educational technology offered is the availability of the opportunity to apply the positive aspects of the current education system.

\section{Main Part}

Moreover, these technologies have a humanistic characteristic of philosophical, psychological, pedagogical, didactic essence. Their humanitarian character is not only theoretically and ideologically oriented to the requirements of the ideology of independence, but also to the practical aspiration to form a highly educated, mature person (Pryanichnikov et al., 2015). They help to strengthen the educational content of the education, to ensure that the content of the material is based on the learner-centered, learner-centered, collaborative, intellectual and ethical development, free and independent thinking. This, in turn, contributes to the improvement of each other's helping dialogue.

In today's education, each student is prepared to succeed only on the basis of his / her own interest in mastering the knowledge, forming in the form of competition, cunning, rudeness, pride, authoritarian qualities. This is in harmony with the requirements of today's educational reform. The essence of these technologies in education is to build on the maturity, critical thinking and individual self-reliance of the trainee. At the same time, it serves as an alternative method for pupils to master and replicate only traditional knowledge in traditional education. These technologies are met methodologically, consistent with the theory of gradual development of the "Uzbek model", allowing education to be based on the evolution of modern educational technologies (Yilmaz \& Bayraktar, 2014).

The application of the proposed educational technologies to the educational process gradually renounces traditional methods and provides access to modern pedagogical and information-communication technologies. They are human-oriented technology with their psychological and pedagogical nature. Collaborative teaching involves interdependent interdependence in the context of teaching, project methodology, classroom learning, and the "reader's folder", and in turn creates a holistic didactic system (Chen et al., 2020; Shaidullin et al., 2014). They train educators in the spirit of honesty, openness, care for others, generosity, sincerity, mutual support.

\section{Results and Discussions}

When using personal learning technologies, you should pay attention to the following:

- learning experience, diversity of knowledge, interest in technology teaching, knowledge level;

- psychological traits of the trainee (memory, perception, perception, self-esteem);

- Characteristics and characteristics of the character of the character.

Thus, the peculiarities of the student's personality should not be overlooked.

Shomirzayev M.Kh. (2021). National followers in the students use of educational technologies instruction of interests. International Journal of Linguistics, Literature and Culture, 7(3), 152-157. https://doi.org/10.21744/ijllc.v7n3.1508 
Collaborative teaching focuses on small groups. His idea was developed by John Dewi, an American philosopher and philosopher (founder of philosophy of philosophy) in the 20th century. However, its technological bases - the practical aspect of coaching in small groups - is a good way to prepare a person for future life, the benefits of teaching for the human being in the 70s and 80s of the 20th century, such as Britain, Canada, Australia, Germany, the Netherlands, China, Japan, Israel in different countries. Its theoretical and ideological basis, in the 80's of the 20th century, was a professor at John Hopkins University, USA. Prof. Rodgers Johnson, David Jokson, Slavic University of Minnesota, and University of California, DG.Aronson, and Sholomo Sharon of Israel's Tel Aviv University. Although cooperative learning differs from one another in the United States, Israel, and European countries, theoretical basis is common.

The US-based collaborative teaching technology focuses on the acquisition of skills and abilities, concepts and theoretical knowledge gained by the student. Cooperative learning in the European and Israeli experience is often based on the organization of discussion on classroom activities. We see that the technology of collaborative education has been developed in many countries of the world and has international significance. This is because he is humane in its essence.

To understand the essence of coaching, let us address one fact in pedagogical practice. This can also mean that students can not fully absorb the learning material during the learning process or make mistakes in practical exercises. "Error" - misinterpretation of the content of the training material, misinterpretation, lack of knowledge and inability to focus on reading. To do this, you have to go through additional training, plus some additional training. It was found out that the error was not analyzed and did not take enough time to communicate with the reader or the material of the pupils.

The pedagogue will make a methodical change to its teaching technology based on this diagnosis. If pupils need more time to master the learning curriculum, they will correct the mistake by collaborating in each group. But his instruction can not help all his students at the same time. That is why the group is responsible for this responsibility. because the idea of partnership is largely assessed not by the appraisal method, but by the whole group of students, so their overall level of proficiency is important.

Self-help students will be able to master the learning material with the help of strong students. As a result of learning, the whole team is interested, not a few readers. The success of the pupil's academic achievement is the responsibility of being involved in the whole group's activities, combining collaboration and sharing the pupils with common goals.

Collaborative teaching has a strong impact on the intellectual and significant development of learners, not only in terms of education but also on the educational side. An important aspect of community education is teamwork, in which students interact, interact, and coordinate their activities. Collaborative teaching is an important tool for the socialization of learners, the formation of communicative skills and skills.

Starting with their childhood, they develop their emotional support and become personal qualities, not in the classroom, but in the way of life and in the life of anybody who comes to the aid of others. So, what is the essence or didactic basis of teaching technology in the partnership? This method ensures the implementation of some or all of the teaching methods that students can accomplish in a consecutive and consistent manner. Or a didactic system that is a complex of techniques that provides a well-defined approach to learning.

Different methods and tools for organizing teaching activities of the students serve to implement common logical, co-operative learning principles. These complexes, in turn, constitute the technological basis for collaborative learning. Only the so-called didactic system can serve as a technology that is tested in the pedagogical process. The didactic system is based on a set of teaching methods, based on theoretical foundations, principles and the concept of education.

Methods and means of selective teaching should be based on the requirements for joint training. We have been teaching collaborative technology in many countries. It is worth noting that it is not everywhere in the same pattern, but the variety of options that can be used to support it. For example, in the John Hopkins University in America, team-based instruction is widely used. The focus is on focusing on the learning group and the success of the group depends on the outcome of each individual member.

Each member of the group works on a topic that is constantly being studied with others. Each member of the team is responsible for solving the common problem, and on the basis of shared knowledge, each member of the team will be able to acquire the necessary skills, skills and skills. It is important for the whole team to know what each student is able to achieve. The whole team is interested in learning about each member of the curriculum. Because the whole team depends on the contribution of each member of the success and the solution of the issue that 
the team has in common. Cooperative Learning Techniques The technology of organizing students' activities is based on three basic principles:

- "Award" will be evaluated as a group score or as a certificate, a praise, a special reward. To accomplish this, one assignment assigned to the entire group is fulfilled.

- The individual responsibility of each student determines the success and failure of the whole team. This allows each member of the group to oversee the activities of others as well as others, helping them to understand and understand the learning material. It ensures that members of the group are ready to evaluate and control their knowledge.

- Groups are based on improving the preceding outcomes of each student's score, which leads to their team's equal opportunities. Comparison of results of acquisition with previous ones gives an opportunity to evaluate the results of this group of students.

The main thing in organizing education is to reward the entire team and to form a sense of individual responsibility. It is important not to give instructions for the student to work together, but the formation of interest in learning each of them is essential. At the same time, comparing the current knowledge of pupils with the results of their previous knowledge is more impressive than their award. This leads to further personal results.

There are four ways to work together in team collaboration - two of them can be used in all subjects taught at a general secondary school or a secondary special vocational college. Cooperative small group - team training; team training in game, tournament form; the other two in most cases, in some subjects, to distinguish between education in the team for a specific age group, ie teaching mathematics; reading, writing essay, giving positive results in collaborative teaching. For example, the organization of collaborative teaching in small groups (in R. Slavic technology) is comprised of four students (boys of varying degrees and boys). At the same time, the teacher will explain the new theme, and then instructs the students to strengthen it in groups, to understand all aspects of it.

The teams will be able to understand the essential aspects of a specific task. Here are some parts of the assignment that each student can learn from his or her part or in the form of a circle as each student reads the next part. The task must be to start a strong or learner, but each task should be open, transparent, and controlled by the whole team. If the assignment is the same for the group, the whole class can discuss the work of different groups in the general lesson after completing the assignment. If the assignment is different, each group can finish separately.

When the teacher is convinced that the learning material is devel- oped by the students, he / she tests them to determine their understanding and apprehension. At the same time, the teacher is individually approaching learners and provides the task, taking into account their level of knowledge. Each student will be summarized and the total value of the group will be announced.

In this case, strong students do not compete with empty students, but every student wants to compete with himself and try to increase their points to the group. This arrangement of education can be used to teach certain concrete and natural sciences in educational institutions. Another aspect of collaborative learning technology is teamto-play activities. As before, the teacher explains a new theme and guides students in group learning. However, they are organizing weekly tournament tournaments among teams to evaluate their results. For this purpose, "tournament tables" consisting of three pupils are organized, which equates to each other. Such teaching gives mathematics more positive results in natural sciences.

The assignments will be differentiated depending on the degree of complexity. Each winner will be given the same amount of points as his team. In this case, the free-throwers compete with their equals and bring points to their team. The team that scores the highest point in the tournament will be announced and rewarded. One of the manifestations of collaborative teaching technology is the individual work in the group. At the same time, according to the results of the previous knowledge, the students undertake individual tasks and perform them on the basis of their work.

In such a form of training, teams can engage in different activities. Team members help each other to fulfill their individual tasks and record their achievements in a special magazine. Final evaluation tests are conducted individually by the pupils themselves (Special Evaluator). Each week, the team members take up the tasks and tasks that each team member has on a program and curriculum basis. At the same time, teachers should emphasize the success of their teams. The ability to work individually with a particular group of learners or pupils increases as students work independently. This organization of the pupils' activities in the process of teaching helps to teach more physics, mathematics, and chemistry.

The way in which collaborative education is embraced and engrossed in creative activities can often be used in subgroups. A group of four students is divided into pairs. When a teacher is working with a couple of instructors, the other one teaches one another the plan and tells it. Separates the main points, writes questions in the text, writes

Shomirzayev M.Kh. (2021). National followers in the students use of educational technologies instruction of interests. International Journal of Linguistics, Literature and Culture, 7(3), 152-157. https://doi.org/10.21744/ijllc.v7n3.1508 
correctly, and runs vocabulary. If a class is not divided into homogeneous groups, all learners collaborate and understand the meaning of the text. Find answers to problematic questions. She is fluent in English and foreign language, and she is involved in writing, writing, interpreting, analyzing and interpreting each other's written works. All work in the group is done by teacher supervision.

Students' knowledge assessment tests take place when teachers are convinced of their complete readiness. Technology of collaborative learning "read together". in which the class consists of 3-5 students of different classes. Each group class will be assigned a part of the general theme. Each member of the group will be able to master the entire study material. The basic principle is to award the entire team, to individual approach to learners, to create equal opportunities for everyone.

The awarding of the group depends on the success of each student. It is important to draw attention to the individual and psychological traits of learners and the exact task of each group. Within the group, each student defines themselves. Groups know this way of learning, with the purpose of creativity (teaching), controlling the responsibilities of social and psychological colleagues, and the culture of interaction. Both objectives of the training are controlled by the instructor.

\section{Conclusion}

The proximity of goals and objectives for the above-mentioned forms of co-operation, as well as the equal opportunities for learners to attend, are individually accountable. At the same time, the group is not a competition, but partnership, the common goal and success of group members is a mutually exclusive factor. It is important to realize that equitable opportunities are the foundation for the development of learners.

\section{Conflict of interest statement}

The author declared that he has no competing interest.

\section{Statement of authorship}

The author has a responsibility for the conception and design of the study. The author has approved the final article.

\section{Acknowledgments}

I am grateful to two anonymous reviewers for their valuable comments on the earlier version of this paper. 


\section{References}

Chen, X., Zou, D., Cheng, G., \& Xie, H. (2020). Detecting latent topics and trends in educational technologies over four decades using structural topic modeling: A retrospective of all volumes of Computers \& Education. Computers \& Education, 151, 103855. https://doi.org/10.1016/j.compedu.2020.103855

Klimov E. A. (1990) Kak vybrat professiyu. -M.

Oudeyer, P. Y., Gottlieb, J., \& Lopes, M. (2016). Intrinsic motivation, curiosity, and learning: Theory and applications in educational technologies. Progress in brain research, 229, 257-284. https://doi.org/10.1016/bs.pbr.2016.05.005

Pryanichnikov, V. E., Katalinic, B., Kirilchenko, A. A., Khelemendik, R. V., Kuvshinov, S. V., Vician, D., \& Uglesic, A. (2015). New creative educational technologies for inter-university network. Procedia Engineering, 100, 259-268. https://doi.org/10.1016/j.proeng.2015.01.366

Shaidullin, R. N., Safiullin, L. N., Gafurov, I. R., \& Safiullin, N. Z. (2014). Blended learning: leading modern educational technologies. Procedia-Social and Behavioral Sciences, 131, 105-110. https://doi.org/10.1016/j.sbspro.2014.04.087

Yilmaz, O., \& Bayraktar, D. M. (2014). Teachers' attitudes towards the use of educational technologies and their individual innovativeness categories. Procedia-social and behavioral sciences, 116, 3458-3461. https://doi.org/10.1016/j.sbspro.2014.01.783

Shomirzayev M.Kh. (2021). National followers in the students use of educational technologies instruction of interests. International Journal of Linguistics, Literature and Culture, 7(3), 152-157. 